\title{
Relationship between airway inflammation and the frequency of exacerbations in patients with smoking related COPD
}

\author{
S Gompertz, D L Bayley, S L Hill, R A Stockley
}

\begin{abstract}
Background-Patients with more frequent exacerbations of chronic obstructive pulmonary disease (COPD) may have increased bronchial inflammation. Airway inflammation was measured in patients who had been thoroughly investigated with full pulmonary function testing, thoracic HRCT scanning, and sputum microbiology to examine further the relationship between exacerbation frequency and bronchial inflammation.

Methods-Airway inflammation (spontaneous sputum sol phase myeloperoxidase (MPO), elastase, leukotriene (LT) $B_{4}$, interleukin (IL)-8, secretory leukoprotenase inhibitor (SLPI), protein leakage) and serum levels of $\mathrm{C}$ reactive protein (CRP) were compared in 40 patients with stable, smoking related COPD, divided into those with frequent ( $\geqslant 3 /$ year) or infrequent $(\leqslant 2 /$ year) exacerbations according to the number of primary care consultations during the preceding year. The comparisons were repeated after excluding eight otherwise clinically indistinguishable patients who had tubular bronchiectasis on the HRCT scan.
\end{abstract}

Results-Patients with frequent $(\mathrm{n}=12)$ and infrequent $(n=28)$ exacerbations were indistinguishable in terms of their clinical, pulmonary function, and sputum characteristics, CRP concentrations, and all of their bronchial inflammatory parameters $(p>0.05)$. The patients without evidence of tubular bronchiectasis $(n=32)$ were equally well matched but the sputum concentrations of SLPI were significantly lower in the frequent exacerbators $(n=8)$ in this subset analysis $(\mathbf{p}<0.05)$.

Conclusions-There are several clinical features that directly influence bronchial inflammation in COPD. When these were carefully controlled for, patients with more frequent reported exacerbations had lower sputum concentrations of SLPI. This important antiproteinase is also known to possess antibacterial and antiviral activity. Further studies are required into the nature of recurrent exacerbations and, in particular, the regulation and role of SLPI in affected individuals.

(Thorax 2001;56:36-41)

Keywords: chronic obstructive pulmonary disease; inflammation; secretory leukoprotease inhibitor (SLPI)
Chronic obstructive pulmonary disease (COPD) comprises a heterogeneous group of conditions, characterised by varying degrees of expiratory airflow limitation, related to combinations of abnormalities in the large and small airways and to alveolar destruction. The patients have a reduced state of health that is (loosely) related to the degree of physiological abnormality. ${ }^{1}$

Recent studies have indicated that the state of health of patients with COPD is also influenced by the presence and frequency ${ }^{2}$ of acute exacerbations. However, these episodes vary in their severity and may remain unreported, ${ }^{2}$ require therapeutic intervention, or even hospital admission. Furthermore, exacerbations are also heterogeneous in nature and are characterised by varying combinations of symptoms ${ }^{3}$ and causes ${ }^{4}$ which may explain why bronchodilators, ${ }^{5}$ antibiotics, ${ }^{3}$ and oral and inhaled corticosteroids ${ }^{67}$ have all been shown to be of benefit.

More recent data indicate that recurrent exacerbations may be associated with increased airway inflammation, ${ }^{8}$ although it is uncertain whether this represents cause or effect. The interpretation of these results is far from clear as many factors may influence inflammation in the airways. These include the presence of chronic bronchitis, ${ }^{9}$ the severity of airflow obstruction, ${ }^{10}$ smoking status, ${ }^{11}$ bronchiectasis, ${ }^{12}$ bacterial colonisation, ${ }^{13}$ treatment with inhaled corticosteroids, ${ }^{14}{ }^{15}$ and the exacerbation itself. ${ }^{16}$

In view of the heterogeneity of both COPD and of exacerbations, comparisons between groups of patients require rigorous stratification for most, if not all, of these confounding factors. Recently Bhowmik et al $l^{8}$ suggested that individuals with COPD who suffer from three or more exacerbations per year have higher sputum concentrations of interleukins 6 (IL-6) and 8 (IL-8) in the stable state than those who have less frequent exacerbations. This observation has major implications for understanding the disease, its exacerbations, and for the development of management policies. However, the clinical characteristics of the two groups of patients described in the study by Bhowmik and colleagues were not reported, making interpretation difficult. Furthermore, the strength of such post hoc analysis depends upon its reproducibility by other workers. In 1996 we embarked upon a study of exacerbations in patients with a primary care diagnosis of COPD. We were able to distinguish two types of exacerbation which were both microbiologically ${ }^{17}$ and biochemically ${ }^{16}$ distinct. We also extensively characterised the patients in 
the stable clinical state ${ }^{18}$ and collected evidence of the number of reported exacerbations in the 12 months before and after our study. We have assessed bronchial and systemic inflammation in those patients with a clear physiological diagnosis of COPD and related this to the number of exacerbations over 12 months as defined by Bhowmik et al. ${ }^{8}$ The results of this analysis form the basis of the present study.

\section{Methods}

STUDY SUBJECTS

Seventy patients who were able to provide a spontaneous sputum sample in the stable clinical state, at least eight weeks after their index exacerbation, were selected from a study designed to characterise the nature of COPD and exacerbations in primary care. ${ }^{17}{ }^{18}$ All had a clinical diagnosis of COPD and chronic bronchitis (daily sputum production for at least three months of two consecutive years) made in the community and had presented to their primary care physician with an acute exacerbation (any combination of worsening respiratory symptoms including one or more of: increased sputum volume, purulence, or breathlessness, with or without other minor symptoms, including increased sputum viscosity, cough, wheeze, chest pain, malaise, fever or rigors). None of the patients were receiving oral corticosteroids at the time of the index exacerbation.

\section{EXACERBATION FREQUENCY}

The primary care records were available for 58 patients $(83 \%)$ and were examined for the 12 months before and after their index exacerbation by an experienced specialist respiratory research nurse. Discrete episodes of worsening respiratory symptoms were identified regardless of whether the consultation resulted in an increase in bronchodilator use or the prescription of an antibiotic or an oral steroid. The patients were divided into those who had presented to their general practitioner with three or more such episodes over the 12 month period preceding the index exacerbation (frequent exacerbators) and those who had suffered two or less exacerbations (infrequent exacerbators).

All 58 patients underwent full pulmonary function testing with reversibility and high resolution computed tomographic CT (HRCT) scanning (1 $\mathrm{mm}$ slices) in the stable state to characterise the nature of their lung disease as described elsewhere. ${ }^{18}$ Forced expiratory volume in one second $\left(\mathrm{FEV}_{1}\right)$, vital capacity (VC), residual volume (RV), total lung capacity (TLC), carbon monoxide transfer factor (TLCO) and transfer coefficient (KCO) were determined according to national guidelines as described previously ${ }^{18}$ and are expressed as percentages of the predicted normal reference values. $\mathrm{FEV}_{1} / \mathrm{VC}$ and RV/TLC were expressed as ratios and multiplied by 100 . Spirometric tests were performed before and 20 minutes after inhalation of $400 \mu \mathrm{g}$ salbutamol. Forty one of the patients $(71 \%)$ had physiological evidence of COPD with both an $\mathrm{FEV}_{1}$ of $<80 \%$ predicted for age, sex, and height and an $\mathrm{FEV}_{1} / \mathrm{VC}$ ratio of $<70 \% .{ }^{19}$ Data from the 17 patients (five frequent, 12 infrequent exacerbators) who did not have airflow obstruction by these criteria were excluded, as were the data from a further patient who had never smoked.

SPUTUM CLASSIFICATION AND PROCESSING Spontaneous sputum samples were obtained over four hours from rising and the macroscopic appearance was allocated a number by an experienced microbiology technician with reference to a standard colour chart. ${ }^{17}$ Values of 0-2 were allocated to samples which were colourless through to white (mucoid), and 3-8 to increasingly purulent samples. Quantitative sputum culture was performed on an aliquot of the sample as described previously. ${ }^{20}$ The remaining sample was centrifuged at $50000 \mathrm{~g}$ at $4^{\circ} \mathrm{C}$ for 90 minutes and the sputum sol phase was harvested and stored at $-70^{\circ} \mathrm{C}$ until analysed. Ten $\mathrm{ml}$ of blood was also obtained, allowed to clot, centrifuged at $3000 \mathrm{rpm}$ for 10 minutes, and the serum was stored at $-70^{\circ} \mathrm{C}$ until required.

Myeloperoxidase (MPO) activity was measured by chromogenic substrate assay relative to a standard preparation of lysed neutrophils ${ }^{21}$ and used as a marker of sputum neutrophil content and activation, expressed as arbitrary units $/ \mathrm{ml}$ of sputum. Neutrophil elastase activity was assessed spectrophotometrically ${ }^{21}$ using the synthetic substrate $\mathrm{Me}$ OSAAPVpNa (Sigma-Aldrich Company Ltd, Poole, Dorset, UK). The lower limit of detection of the assay was $0.8 \mathrm{nM}$ and sample results below this level were taken as zero for statistical purposes.

The neutrophil chemoattractants IL-8 and leukotriene $\mathrm{B}_{4}\left(\mathrm{LTB}_{4}\right)$ and the bronchial protease inhibitor secretory leukoprotease inhibitor (SLPI) were measured using commercially available ELISA kits (IL-8 and SLPI: R\&D Systems Europe Ltd, Abingdon, UK; $\mathrm{LTB}_{4}$ : Amersham International plc, Buckinghamshire, UK). The characteristics and recovery of these assays have been described previously. $^{21}$

Sputum sol and serum albumin were measured by radial immunodiffusion using a commercially available kit (The Binding Site Ltd, Birmingham, UK). Sputum sol/serum ratios (expressed as a percentage) were calculated, providing an assessment of protein "leakage" from the blood into the lung. ${ }^{21}$

\section{SERUM C REACTIVE PROTEIN}

Serum levels of $\mathrm{C}$ reactive protein (CRP) were measured in 35 of the 40 patients (11 frequent, 24 infrequent exacerbators) by radial immunodiffusion using a commercially available kit (The Binding Site Limited, Birmingham, UK) with an interassay coefficient of variation of $2.2 \%$. Five $\mu 1$ of standard or sample was added to each well and the plate was incubated for at least 72 hours at room temperature. Precipitation ring diameters were measured using an eye piece graticule and a regression curve was constructed of the square of the diameter of the precipitation ring versus concentration of the 


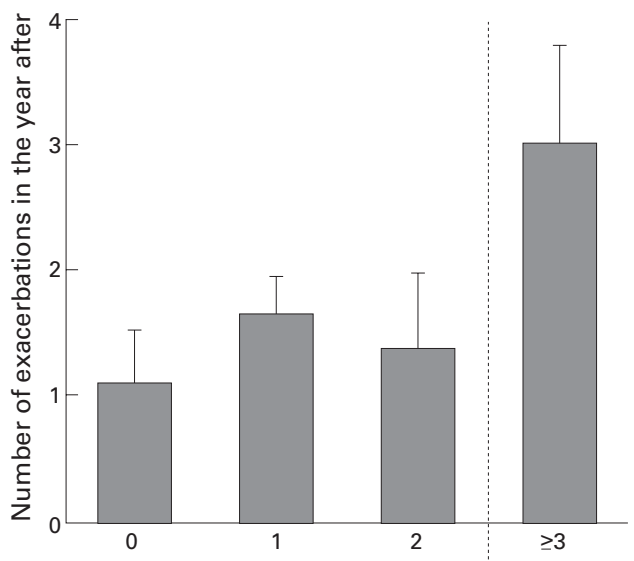

Number of exacerbations in the year before the index exacerbation

Figure 1 Number of exacerbations in the 12 months before and after the study. Patients were grouped into those who had infrequent exacerbations ( $\leqslant 2$ in the 12 months prior to the study) and those with more frequent exacerbations $(\geqslant 3)$. The number of exacerbations in the year after the study is shown as mean (SE). There was a significant correlation (Spearman) between the number of exacerbations in each year $(r=0.32, p<0.03)$.

standards. The concentration of protein in the unknown samples was calculated by interpolation from this standard curve. The lower limit of detection for this assay is $2 \mathrm{mg} / \mathrm{l}$ and sample results below this level were taken as zero for statistical purposes.

STATISTICAL ANALYSIS

All statistical analyses were performed using the SPSS statistical package (Version 8.0. Chicago, USA). Demographic data (except smoking history) were normally distributed and are expressed as mean (SD), and the patient groups were compared using non-paired $t$ tests. Fisher's exact test was used to compare categorical data. Inflammatory data and smoking history (in pack years) were not normally distributed and are expressed as median (interquartile range). Differences between patient groups were compared with the MannWhitney $U$ test and the level of statistical significance was taken as $\mathrm{p}<0.05$.

Previous work by our group (unpublished data) has indicated that, although clinically indistinguishable, patients with tubular bronchiectasis have evidence of increased airway inflammation (neutrophil elastase, IL-8 and $\mathrm{LTB}_{4}$ ). An a priori decision was therefore taken to perform a subset analysis having excluded these individuals.

The study was approved by the South Birmingham Health Authority ethics committee and all subjects provided written informed consent.

\section{Results}

ALL PATIENTS

The 40 patients eventually studied had consulted their primary care physician with up to 10 exacerbations in the 12 months before the study (median (IQR) $1.5(1.0-3.0)$ ) and this was similar $(\mathrm{p}>0.05)$ to the exacerbation rate in the 12 months after the study (median (IQR) $2.0(0.0-3.0))$. In general there was a consist-
Table 1 Demographic and pulmonary function data (all patients)

\begin{tabular}{|c|c|c|}
\hline & $\begin{array}{l}\text { Frequent } \\
\text { exacerbators } \\
(n=12)\end{array}$ & $\begin{array}{l}\text { Infrequent } \\
\text { exacerbators } \\
(n=28)\end{array}$ \\
\hline Age (years) & $67.3(4.9)$ & $66.7(7.2)$ \\
\hline Male sex $\dagger$ & $6(50 \%)$ & $18(64 \%)$ \\
\hline Current smokers $\dagger$ & $5(42 \%)$ & $15(54 \%)$ \\
\hline Inhaled steroids $\dagger$ & $10(83 \%)^{\star}$ & $13(46 \%)$ \\
\hline $\mathrm{FEV}_{1}(\mathrm{l})$ & $1.24(0.48)$ & $1.19(0.35)$ \\
\hline $\mathrm{FEV}_{1}(\%)$ & $52.3(13.8)$ & $48.2(15.4)$ \\
\hline $\begin{array}{l}\text { Response to inhaled } \beta_{2} \\
\text { agonists }(\mathrm{ml})\end{array}$ & 225 (130) & $175(145)$ \\
\hline $\mathrm{FEV}_{1} / \mathrm{VC}(\%)$ & $43.5(10.3)$ & $43.3(12.6)$ \\
\hline RV/TLC (\%) & $118.8(25.3)$ & $124.8(22.2)$ \\
\hline Kсо (\%) & $93.7(33.8)$ & $91.0(26.5)$ \\
\hline
\end{tabular}

$\mathrm{FEV}_{1}=$ forced expiratory volume in one second; $\mathrm{VC}=$ vital capacity; RV = residual volume; TLC = total lung capacity; KCO $=$ carbon monoxide transfer coefficient.

Frequent exacerbators had suffered $\geqslant 3$ and infrequent exacerbators $\leqslant 2$ exacerbations in the previous 12 months.

tClinical characteristics expressed as number (\%); the remainder of the data are shown as mean (SD).

*Significant difference $(\mathrm{p}<0.05)$ in the proportion of patients receiving inhaled corticosteroids.

ent relationship $(r=0.32, \mathrm{p}<0.03)$ between the number of exacerbations reported each year (fig 1). The 28 patients (70\%) who had experienced $\leqslant 2$ exacerbations in the 12 months preceding the study $(1.0(0.0-2.0))$ had a similar number $(\mathrm{p}>0.05)$ in the second year $\left(1.0\left(0.0_{-}\right.\right.$ $2.8)$ ). However, the 12 patients $(30 \%)$ who had $\geqslant 3$ exacerbations in the year before the study $(4.0(3.0-5.8))$ had fewer $(\mathrm{p}<0.05)$ in the subsequent 12 months $(2.0(1.0-4.0))$. Twenty of the 28 patients with $\leqslant 2$ exacerbations $(71 \%)$ had very few exacerbations $(0-1)$ in the year preceding the index exacerbation, indicating that the selection criteria did not exclude those patients with the lowest exacerbation frequencies.

All patients (by the selection criteria described) had smoked, and both groups had a similar history of cigarette consumption with a median (IQR) pack year history of 35 (25-56) and 57 (33-77) for the frequent and infrequent exacerbators, respectively $(\mathrm{p}>0.05)$. Although there were no differences in age or in the proportions of men or of current smokers between the two groups, a higher proportion $(p<0.05)$ of frequent exacerbators were receiving inhaled corticosteroids at the onset of the index exacerbation. The demographic data for both groups are summarised in table 1 .

Patients in both groups displayed the full range of airflow obstruction with $\mathrm{FEV}_{1}$ values of $19.0-71.2 \%$ predicted in those with frequent exacerbations and $18.1-79.9 \%$ predicted in patients with infrequent exacerbations. The severity of airflow obstruction was similar with no differences in pre-bronchodilator $\mathrm{FEV}_{1}$, $\mathrm{FEV}_{1} / \mathrm{VC}$ ratio, or the response to inhaled $\beta_{2}$ agonists (table 1). Furthermore, there were no differences in the degree of gas trapping (measured as the ratio of residual volume to total lung capacity, RV/TLC) or in gas transfer corrected for lung volume (KCO).

The mean (SD) sputum colour in the stable state was the same (2.6 (1.0)) for both the frequent and infrequent exacerbators. Potential respiratory pathogens were isolated from the sputum of three $(25 \%)$ of the patients with frequent exacerbations and from 11 (39\%) of 
Table 2 Bronchial inflammation according to exacerbation frequency (all patients)

\begin{tabular}{cllllll}
\hline & $\begin{array}{l}M P O \\
(\text { units/ml })\end{array}$ & $\begin{array}{l}\text { Elastase } \\
(n M)\end{array}$ & $\begin{array}{l}\mathrm{LTB}_{4} \\
(n M)\end{array}$ & $\begin{array}{l}I L-8 \\
(n M)\end{array}$ & $\begin{array}{l}\text { SLPI } \\
(\mu M)\end{array}$ & $\begin{array}{l}\text { Sol:serum } \\
\text { albumin ratio } \\
(\%)\end{array}$ \\
\hline $\begin{array}{c}\text { Frequent } \\
(\mathrm{n}=12)\end{array}$ & 0.41 & 0.00 & 3.48 & 3.1 & 2.9 & 0.35 \\
$\begin{array}{c}\text { Infrequent } \\
(\mathrm{n}=28)\end{array}$ & $(0.31-0.59)$ & $(0.00-9.05)$ & $(1.6-5.7)$ & $(0.9-6.8)$ & $(1.9-6.0)$ & $(0.30-0.93)$ \\
\hline
\end{tabular}

$\mathrm{MPO}=$ myeloperoxidase $; \mathrm{LTB}_{4}=$ leukotriene $\mathrm{B}_{4} ; \mathrm{IL}-8=$ interleukin $8 ;$ SLPI = secretory leukoprotease inhibitor.

Frequent exacerbators had suffered from $\geqslant 3$ exacerbations in the previous 12 months; infrequen exacerbators from $\leqslant 2$ exacerbations.

The concentrations of the inflammatory mediators are recorded as median (IQR). There were no significant differences between the frequent and infrequent exacerbators $(p>0.05)$

Table 3 Demographic and pulmonary function data (patients with no bronchial dilatation on high resolution CT scan)

\begin{tabular}{lll}
\hline & $\begin{array}{l}\text { Frequent } \\
\text { exacerbators } \\
(n=8)\end{array}$ & $\begin{array}{l}\text { Infrequent } \\
\text { exacerbators } \\
(n=24)\end{array}$ \\
\hline Age (years) & $66.4(5.0)$ & $66.7(6.9)$ \\
Male sex† & $5(63 \%)$ & $16(67 \%)$ \\
Current smokers $\dagger$ & $4(50 \%)$ & $12(50 \%)$ \\
Inhaled steroidst & $7(88 \%)^{\star}$ & $12(50 \%)$ \\
FEV $_{1}(1)$ & $1.25(0.50)$ & $1.15(0.33)$ \\
FEV $_{1}(\%)$ & $50.5(14.9)$ & $46.5(14.6)$ \\
${\text { Response to inhaled } \beta_{2}}_{2}$ & $225(55)$ & $170(135)$ \\
$\quad$ agonist (ml) & $41.6(11.5)$ & $42.3(12.5)$ \\
FEV $/$ VC (\%) & $120(27)$ & $125(23)$ \\
RV/TLC (\%) & $91.0(28.7)$ & $90.8(27.2)$ \\
Kco (\%) & & \\
\hline
\end{tabular}

$\mathrm{FEV}_{1}=$ forced expiratory volume in one second; $\mathrm{VC}=$ vital capacity; RV = residual volume; TLC = total lung capacity; $\mathrm{KCO}$ $=$ carbon monoxide transfer coefficient.

Frequent exacerbators had suffered $\geqslant 3$ and infrequent exacerbators $\leqslant 2$ exacerbations in the previous 12 months.

†Clinical characteristics expressed as number (\%); the remainder of the data are shown as mean (SD).

* Proportion of patients on inhaled corticosteroids in the frequent exacerbation group was higher $(p=0.05)$.

those with infrequent exacerbations ( $p>0.05$ ) and the proportion from whom high bacterial loads $\left(>10^{7} \mathrm{cfu} / \mathrm{ml}\right)$ were recovered was the same $(17 \%$ in the frequent group and $25 \%$ in the infrequent group; $\mathrm{p}>0.05)$.

The median (IQR) concentrations of the sputum inflammatory parameters are shown in table 2. There were no significant differences in the concentrations of MPO, elastase, $\mathrm{LTB}_{4}$, IL-8, SLPI, or protein leakage between the two groups. Five $(42 \%)$ of the frequent exacerbators had detectable sputum elastase activity, as did nine $(32 \%)$ of the infrequent exacerbators $(p>0.05)$. Furthermore, there were no significant differences in the concentrations of CRP: $3.0(1.0-11.9) \mathrm{mg} / \mathrm{l}$ and $2.7(1.0-7.4) \mathrm{mg} / 1$, respectively, in those with frequent and infrequent exacerbations.

An annual exacerbation rate was also calculated using the data from the two consecutive

Table 4 Bronchial inflammation according to exacerbation frequency (patients with no bronchial dilatation)

\begin{tabular}{|c|c|c|c|c|c|c|}
\hline & $\begin{array}{l}\text { MPO } \\
\text { (units/ml) }\end{array}$ & $\begin{array}{l}\text { Elastase } \\
(n M)\end{array}$ & $\begin{array}{l}\mathrm{LTB}_{4} \\
(n M)\end{array}$ & $\begin{array}{l}I L-8 \\
(n M)\end{array}$ & $\begin{array}{l}S L P I \\
(\mu M)\end{array}$ & $\begin{array}{l}\text { Sol:serum } \\
\text { albumin ratio } \\
(\%)\end{array}$ \\
\hline $\begin{array}{l}\text { Frequent } \\
(n=8)\end{array}$ & $\begin{array}{l}0.37 \\
(0.16-0.49)\end{array}$ & $\begin{array}{l}0.00 \\
(0.00-6.40)\end{array}$ & $\begin{array}{l}2.7 \\
(0.9-5.6)\end{array}$ & $\begin{array}{l}2.2 \\
(0.9-6.2)\end{array}$ & $\begin{array}{l}2.2 \\
(1.4-3.8)\end{array}$ & $\begin{array}{l}0.30 \\
(0.30-0.68)\end{array}$ \\
\hline $\begin{array}{l}\text { Infrequent } \\
\quad(\mathrm{n}=24)\end{array}$ & $\begin{array}{l}0.30 \\
(0.14-0.66)\end{array}$ & $\begin{array}{l}0.00 \\
(0.00-6.83)\end{array}$ & $\begin{array}{l}4.5 \\
(1.9-6.8)\end{array}$ & $\begin{array}{l}2.7 \\
(0.9-6.5)\end{array}$ & $\begin{array}{l}4.5^{\star} \\
(3.2-5.5)\end{array}$ & $\begin{array}{l}0.59 \\
(0.28-1.21)\end{array}$ \\
\hline
\end{tabular}

$\mathrm{MPO}=$ myeloperoxidase $\mathrm{LTB}_{4}=$ leukotriene $\mathrm{B}_{4} ; \mathrm{IL}-8=$ interleukin 8 ; SLPI = secretory leukoprotease inhibitor.

Frequent exacerbators had suffered from $\geqslant 3$ exacerbations in the previous 12 months; infrequent exacerbators from $\leqslant 2$ exacerbations.

The concentrations of the inflammatory mediators are shown as median (IQR).

${ }^{\star}$ Concentration of sputum SLPI was significantly lower in the infrequent exacerbators $(p<0.05)$. years and the same inflammatory parameters were compared between those with frequent exacerbations ( $\geqslant 3$ per annum, $\mathrm{n}=11$ ) and those with infrequent exacerbations $(\leqslant 2$ per annum, $n=23$ ), having excluded the six patients with borderline exacerbation frequencies $(>2$ but $<3$ per annum). Again there were no differences in any of the inflammatory parameters between the two groups $(p>0.05)$.

\section{INFLUENCE OF BRONCHIECTASIS}

Eight $(20 \%)$ of the patients with a clinical and physiological diagnosis of COPD (four with frequent and four with infrequent exacerbations) had radiological evidence of mild tubular bronchiectasis on the HRCT scan, as described previously, ${ }^{18}$ although they were indistinguishable clinically from those without bronchial dilatation. These patients were excluded and a further comparison between frequent and infrequent exacerbators was carried out in the remaining subgroup, as per our a priori decision. The demographic and pulmonary function data of these remaining 32 individuals (eight frequent and 24 infrequent exacerbators) are summarised in table 3.

The two groups were similar with no differences in age, lung function, the proportion of men, or current smokers between them (table 3). Pack year smoking histories were also similar: $31(25-70)$ in the group with frequent exacerbations and $61(33-91)$ in those with infrequent exacerbations $(p>0.05)$. However, the proportion of frequent exacerbators receiving inhaled corticosteroids at the onset of the index exacerbation remained higher ( $88 \%$ vs $50 \%)$.

The sputum characteristics of the two subgroups also remained the same ( $p>0.05$ for all parameters). The mean (SD) sputum colour was $2.3(0.7)$ in the frequent exacerbators and 2.6 (1.0) in the infrequent exacerbators. Potential respiratory pathogens were isolated from the sputum samples of two $(25 \%)$ of those with frequent exacerbations and from nine $(38 \%)$ of the patients with infrequent exacerbations and the proportion in whom a high bacterial load $\left(>10^{7} \mathrm{cfu} / \mathrm{ml}\right)$ was recovered was also the same (one (13\%) and five (21\%), respectively).

In this subgroup analysis there were still no differences in the sputum sol MPO, elastase, $\mathrm{LTB}_{4}$, IL-8 levels or protein leakage between the two groups ( $p>0.05$, table 4$)$. Two of the frequent exacerbators (25\%) had detectable sputum elastase activity, as did seven $(29 \%)$ of the infrequent exacerbators $(p>0.05)$. CRP concentrations were no different $(p>0.05)$ between the two groups of patients, being 2.8 $(1.3-4.8) \mathrm{mg} / \mathrm{l}$ and $3.1(1.0-8.6) \mathrm{mg} / \mathrm{l}$, respectively. However, those who had experienced $\geqslant 3$ exacerbations over the preceding 12 months had lower sputum SLPI concentrations $(\mathrm{p}<0.05$; table 4 and fig 2$)$. Furthermore, there was a significant inverse (Spearman) correlation between exacerbation frequency (determined over the preceding year) and sputum SLPI concentration $(r=-0.49, \mathrm{p}<0.005)$. 


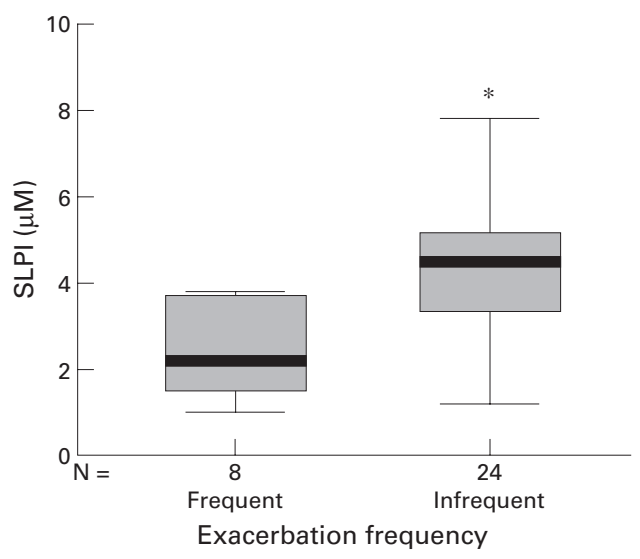

Figure 2 Sputum concentrations of secretory leukoprotease inhibitor (SLPI) in patients without bronchial dilatation on high resolution CT scanning. The median is indicated by the bold horizontal line, the box represents the interquartile range, and the whiskers define the range (excluding outlying and extreme values - that is, points with values at least 1.5 box lengths from the upper or lower limits of the box).

${ }^{*} p<0.05$, difference between the two groups.

\section{Discussion}

In this study, in which we have compared inflammatory mediators, we have gone to great lengths to characterise the patients' disease, both clinically and also in terms of their sputum bacterial load and HRCT appearances, in order to identify as many potential confounding factors as possible. There were no differences in the severity of airflow obstruction, current smoking status, or in the prevalence or degree of airway colonisation, all of which are known to influence bronchial inflammation. ${ }^{10}{ }^{11}{ }^{13}$ Although the proportion of patients receiving inhaled corticosteroids was greater in the group who had experienced frequent exacerbations, there was no observable effect of corticosteroids on bronchial inflammation in either group (data not shown; $\mathrm{p}>0.05$ for all parameters). Inhaled corticosteroids may have some beneficial effects on bronchial inflammation, including reducing airway neutrophilia, ${ }^{14}$ reducing protein leakage ${ }^{16}$ and possibly increasing SLPI concentrations. ${ }^{15}$ Corticosteroids are also known to reduce both the number and severity of exacerbations in COPD, ${ }^{72}$ and the difference observed in corticosteroid use is therefore likely to reflect a different prescribing practice for patients attending the surgery more frequently.

We examined six markers of neutrophilic bronchial inflammation but found no differences in any of these parameters between the two groups of patients, which may reflect the similarity of our patients. In particular, there were no differences in the concentration of IL-8, which is known to be affected by airflow obstruction, smoking history, or bacterial colonisation $^{1011}{ }^{13}$ Furthermore, there were no differences in systemic inflammation assessed by CRP levels.

Bhowmik et al reported results from 44 patients with COPD in whom sputum induction was performed in the stable state. They found raised levels of IL- 6 and IL- 8 in those who had suffered frequent exacerbations over the previous 12 months. Although the authors described the clinical characteristics of their whole population, they did not compare the characteristics of the 44 patients who had provided the stable state data ( 21 frequent and 23 infrequent exacerbators). Furthermore, there was no information concerning current smoking status, bacterial colonisation, or use of inhaled corticosteroids, all of which may have influenced the results. Thus, the differences in IL- 6 and IL- 8 observed by Bhowmik et al ${ }^{8}$ are difficult to interpret in isolation. It is possible that frequent exacerbations may have a continuing influence on bronchial inflammation even in the stable clinical state, as frequent exacerbators are more likely to have been studied closer to an exacerbation. Alternatively, the differences in inflammation may have been related to unreported, undetected, or uncontrolled for clinical differences between the two groups of patients, or even to a different response to sputum induction which is known to be a pro-inflammatory stimulus. ${ }^{23}$

Bhowmik et $a l^{8}$ collected their data relating to exacerbation numbers prospectively from a highly trained outpatient population who filled in symptom diary cards on a daily basis, whereas our data were obtained retrospectively from analysis of primary care records. Furthermore, other workers ${ }^{24}$ have shown that reconsultation rates for acute lower respiratory tract infection in the general population are closely related to past consulting behaviour. It is possible that either of these factors could explain the lack of a difference in inflammation between the two patient groups in our population. Nevertheless, the design of the study determined that only exacerbation symptoms reported to the primary care physician were identified, rather than the $50 \%$ or so of exacerbations which may remain unreported, ${ }^{2}$ and these were therefore likely to be of more clinical significance.

In our subgroup analysis we excluded patients with bronchial dilatation seen on HRCT scanning whom we have found previously to have increased bronchial inflammation. In the remaining 32 patients the concentrations of SLPI were significantly lower in the sputum of those with frequent exacerbations. This observation merits further study because SLPI is not only a protease inhibitor ${ }^{25}$ but also has antiviral and antibacterial activity. ${ }^{26}$ Factors influencing SLPI concentrations in the airway are largely unknown, although elastase ${ }^{27}$ and bacterial endotoxin (unpublished data) will reduce its release from epithelial cells. However, it is unlikely that either mechanism explains our findings as there was little detectable elastase activity in either group of patients in the stable state and the proportion colonised with bacteria was also similar. Steroids can increase both SLPI production by epithelial cells in vitro ${ }^{28}$ and concentrations in lung secretions in vivo. ${ }^{15}$ However, the group with low SLPI levels were frequent exacerbators and more of this group were receiving inhaled steroids, which would (if anything) reduce the difference observed. 
At present we cannot exclude a chance finding of differences in SLPI concentration between our two groups of patients. However, it is tempting to speculate that a reduction in the antibacterial/antiviral function of SLPI would predispose to more frequent exacerbations related to these organisms. In addition, low concentrations of SLPI would result in greater local elastase activity during exacerbations ${ }^{29}$ leading to increased epithelial damage and reduced ciliary beat frequency ${ }^{30}$ which might also predispose to more bacterial exacerbations. Clearly, further studies are indicated to try to reproduce these findings in a larger number of patients.

In summary, there are several clinical features that directly influence bronchial inflammation in COPD. When these were carefully controlled for patients with more frequent reported exacerbations did not have significantly greater bronchial inflammation. Clearly, the relationship between frequent exacerbations, bronchial inflammation, and lung defence is of major importance in understanding the pathogenesis of COPD. Further studies are required into the nature of recurrent exacerbations and also the regulation and role of SLPI in larger numbers of affected individuals.

This study was funded by GlaxoWellcome who provided an unrestricted educational grant. The authors also wish to acknowledge all the hard work of $\mathrm{M}$ Henson and $\mathrm{H}$ Whitehouse (specialist research nurses) who collected the exacerbation frequency data.

1 Ketelaars CAJ, Schlosser MAG, Mostert R, et al. Determinants of health related quality of life in patients with chronic obstructive pulmonary disease. Thorax 1996;51:39-43.

2 Seemungal TAR, Donaldson GC, Paul EA, et al. Effect of exacerbation on quality of life in patients with chronic obstructive pulmonary disease. Am $\mathcal{f}$ Respir Crit Care Med obstructive pulmon

3 Anthonisen NR, Manfreda J, Warren CPW, et al. Antibiotic therapy in exacerbations of chronic obstructive pulmonary therapy in exacerbations of chronic obstructive
disease. Ann Intern Med 1987;106:196-204.

4 Wilson R. The role of infection in COPD. Chest 1998;113. Wilson R.

5 Berry RB, Shinto RA, Wong FH, et al. Nebulizer vs spacer for bronchodilator delivery in patients hospitalized for acute exacerbations of COPD. Chest 1989;96:1241-6.

6 Thompson WH, Nielson CP, Carvalho P, et al. Controlled trial of oral prednisone in outpatients with acute COPD exacerbation. Am ₹ Respir Crit Care Med 1996;154:407-12.

7 Paggiaro PL, Dahle R, Bakrani I, et al. Multicentre randomised placebo-controlled trial of inhaled fluticasone propionate in patients with chronic obstructive pulmonary disease. Lancet 1998;351:773-80.

8 Bhowmik A, Seemungal TAR, Sapsford RJ, et al. Relationship of sputum inflammatory changes to symptoms and lung function changes in COPD exacerbations. Thorax lung function chan
9 Stanescu D, Sanna A, Veriter C, et al. Airways obstruction, chronic expectoration, and rapid decline of $\mathrm{FEV}_{1}$ in smokers are associated with increased levels of neutrophils. Thorax 1996;51:267-71.

10 Yamamoto C, Yoneda T, Yoshikawa M, et al. Airway inflammation in COPD assessed by sputum levels of interleukin-8. Chest 1997;112:505-10.

11 Hill AT, Bayley DL, Campbell EJ, et al. Airways inflammation in chronic bronchitis: the effects of smoking and $\alpha-1-$ antitrypsin deficiency. Eur Respir 7 2000;15:886-90.

12 Gaga M, Bentley AM, Humbert M, et al. Increases in CD4+ $\mathrm{T}$ lymphocytes, macrophages. neutrophils and interleukin 8 positive cells in the airways of patients with bronchiectasis. Thorax 1998;53:685-91.

13 Hill AT, Campbell EJ, Hill SL, et al. Association between airway bacterial load and markers of airway inflammation in patients with stable chronic bronchitis. Am f Med 2000; 109:288-95.

14 Confalonieri M, Mainardi E, Della Porta R, et al. Inhaled corticosteroids reduce neutrophilic bronchial inflammation in patients with chronic obstructive pulmonary disease. Thorax 1998;53:583-5.

15 Llewellyn-Jones CG, Harris TAJ, Stockley RA. Effect of fluticasone propionate on sputum of patients with chronic bronchitis and emphysema. Am $\mathcal{F}$ Respir Crit Care Med 1996;153:616-21.

16 Gompertz S, O'Brien C, Bayley, et al. Changes in bronchial inflammation during acute exacerbations of chronic bronchitis. Eur Respir $\mathcal{F} 2000$ (in press).

17 Stockley RA, O'Brien C, Pye A, et al. Relationship of sputum colour to nature and outpatient management of acute exacerbations of COPD. Chest 2000;117:1683-45.

18 O'Brien C, Guest PJ, Hill SL, et al. Physiological and radiological characterisation of patients diagnosed with chronic obstructive pulmonary disease in primary care. Thorax 2000;55:635-42.

19 British Thoracic Society. BTS guidelines for the management of chronic obstructive pulmonary disease. Thorax 1997;52(Suppl 5):S1-28.

20 Pye A, Stockley RA, Hill SL. Simple method for quantifying viable bacterial numbers in sputum. F Clin Pathol 1995;48: $719-24$

21 Hill AT, Bayley D, Stockley RA. The interrelationship of sputum inflammatory markers in patients with chronic
bronchitis. Am 7 Respir Crit Care Med 1999;160:893-8.

22 Burge PS, Calverley PMA, Jones PW, et al. Randomised, double blind, placebo controlled study of fluticasone propionate in patients with moderate to severe chronic obstructive pulmonary disease: the ISOLDE trial. $B M \mathcal{F}$ 2000;320:1297-303.

23 Pavord ID. Sputum induction to assess airway inflammation: is it an inflammatory stimulus? Thorax 1998;53:79-80.

24 Holmes WF, MacFarlane JT, MacFarlane RM, et al. The influence of antibiotics and other factors on reconsultation for acute lower respiratory tract illness in primary care. $\mathrm{Br}$ for acute lower respiratory $1997 ; 47: 815-8$.

25 Stockley RA. Cellular mechanisms in the pathogenesis of COPD. Eur Respir Rev 1996;6:264-9.

26 Tomee JFC, Koëter GH, Hiemstra PS, et al. Secretory leukoprotease inhibitor: a native antimicrobial protein presenting a new therapeutic option? Thorax 1998;53:114-6.

27 Sallenave J-M, Shulmann J, Crossley J, et al. Regulation of secretory leukocyte protease inhibitor (SLPI) and elastasespecific inhibitor (ESI/elafin) in human airway epithelial cells by cytokines and neutrophilic enzymes. Am $\mathcal{F}$ Respir Cell Mol Biol 1994:11:733-741.

28 Abbinante-Nissen JA, Simpson LG, Leikauf GD. Corticosteroids increase secretory leukocyte protease inhibitor transcript levels in airway epithelial cells. Am $\mathcal{F}$ Physiol 1995;268:L601-6.

29 Stockley RA, Burnett D. Alpha1-antitrypsin and leukocyte elastase in infected and non-infected sputum. Am Rev Respir Dis 1979;120:1081-6.

30 Gompertz S, Stockley RA. Inflammation: role of the neutrophil and the eosinophil. Semin Respir Infect 2000;15:14-23. 